\title{
Emotional Intelligence and Administrative Effectiveness of Provosts of Federal Training Centres in Nigeria
}

\author{
Adedokun Adeniyi Nureni \\ Department of Public Administration Federal Training Centre, Ilorin, Nigeria
}

\begin{abstract}
This study investigated the correlation between emotional intelligence and administrative effectiveness of Provosts of Federal Training Centres in Nigeria. It employed the use of descriptive correlation research method, 12 Provosts and Deputy Provosts (academic), and 149 lecturers of the six Federal Training Centres in Nigeria. Questionnaire was used in data collection with reliability value of .981. Five operational research hypotheses were formulated and tested using Pearson-product moment correlation and t-test statistics to analyze data. The results revealed that there is a strong, positive correlation between emotional intelligence and administrative effectiveness of provosts surveyed with calculated $r$-value .785 greater than the critical $r$ value .532 at .05 level of significance. Based on the findings, it was recommended among others that provosts of Federal Training Centres in Nigeria should regularly update themselves on the four domains of emotional intelligence because of the impacts these competencies could have on their administrative effectiveness and ultimately the school effectiveness.
\end{abstract}

Keywords: Administrative Effectiveness, Emotional Intelligence, Provosts, Competencies, Leadership Practices

\section{Introduction}

The Provosts of Federal Training Centres deal with an institution that is becoming increasingly complex and technologically sophisticated. These institutions are expected to train lower and middle grade workers of the federal public service that must be up to task in the millennium goal service delivery. Reforms are churned day-in day-out for relevant public service in the new global dispensation. Given these new demands and the complexity of the job, ascending through the ranks from classroom teaching to an administrative position is inadequate preparation for directing a complicated organization. Provosts of these institutions need to be acquainted with the competencies necessary to function effectively in the current complex public service organization.

Reforms and frequent policies changes require Provosts in these Centres to embrace seriously their responsibility to ensure good school climate where students achieve at high levels. Therefore, Provosts striving to be accountable to this charge must identify what, within their own leadership practices, makes a difference in student achievement. The provosts' effectiveness should be seen in the achievement of the educational objectives and goals of the centre. Marzano, Waters, \& McNulty (2005) conducted a study to determine leadership practices, which could positively impact student achievement. Consistent with this latest strand of research - a focus on the person of the principal, this study considers the importance of the person of the school head as leader, with special attention given to emotional intelligence. An effective leadership that enhances organizational performance has of recent been linked to emotional intelligence (Goleman, Boyatzis, \& McKee, 2002). When put into perspective these studies by Marzano, Waters, \& McNulty (2005) and Goleman, Boyatzis \& McKee (2002) could assist school leaders to understand various ways of strengthening their administrative effectiveness to positively impact student achievement. The purpose of this study was to explore the connection between emotional intelligence in school principals and their engagement in leadership practices that enhance administrative effectiveness. Specifically, the study was conducted to determine if a relationship exists between emotional intelligence and the administrative effectiveness.

\section{Administrative Effectiveness Competencies}

The responsibility of a school leader is to ensure that the school goals and objectives are achieved. The prescribed roles of a school leader cannot be meaningfully divorced from the parameters of his effectiveness. Oduwaiye (2006) describes administrative effectiveness as the achievement of operative goals, capabilities, experiences, energy goals and value as well as the satisfaction derived by members and subsequently the internal structure and operation of the organization. Administrative effectiveness is the ability to get all members of the school community to work together towards the achievement of the excellent goal of the education of all the students. It implies extent to which employees in the school system are motivated and given adequate direction with a view to achieving institutional goals. 
Nwagwu (1999) opines that any attempt to evaluate the effectiveness of the performance of a school head must first determine what skills the person possess and exhibit in his administrative functions and activities. The personality of a school head as well as what he does, how he does it, and the results he achieved are among variables and factors to be considered when assessing his effectiveness. Rob (2010) aligns with Nwagwu (1999) when he holds that an administrator is efficient and effective if such leader possesses high selfawareness of his responsibility and control. This means that the way and manner a manager carries out these constructs will determine his administrative effectiveness. Marzano, Waters, \& McNulty (2005) in a study identified 21 categories of leadership practices which are referred to as leadership responsibilities. These responsibilities are found to possess positive impact on student achievement. These include Achievement; Affirmation; Change Agent; Communication; Contingent Rewards; Culture; Discipline; Flexibility; Focus; Ideals and Beliefs; Input; Intellectual Stimulation; Involvement in Curriculum, Instruction, and Assessment; Knowledge of Curriculum, Instruction, and Assessment; Monitor and Evaluate; Optimize; Order; Outreach; Relationships; Resources; Situational Awareness, and Visibility. TABLE 1 provides specific definitions for each of these 21 leadership practices.

Table 1: Definitions of School Leadership Practices

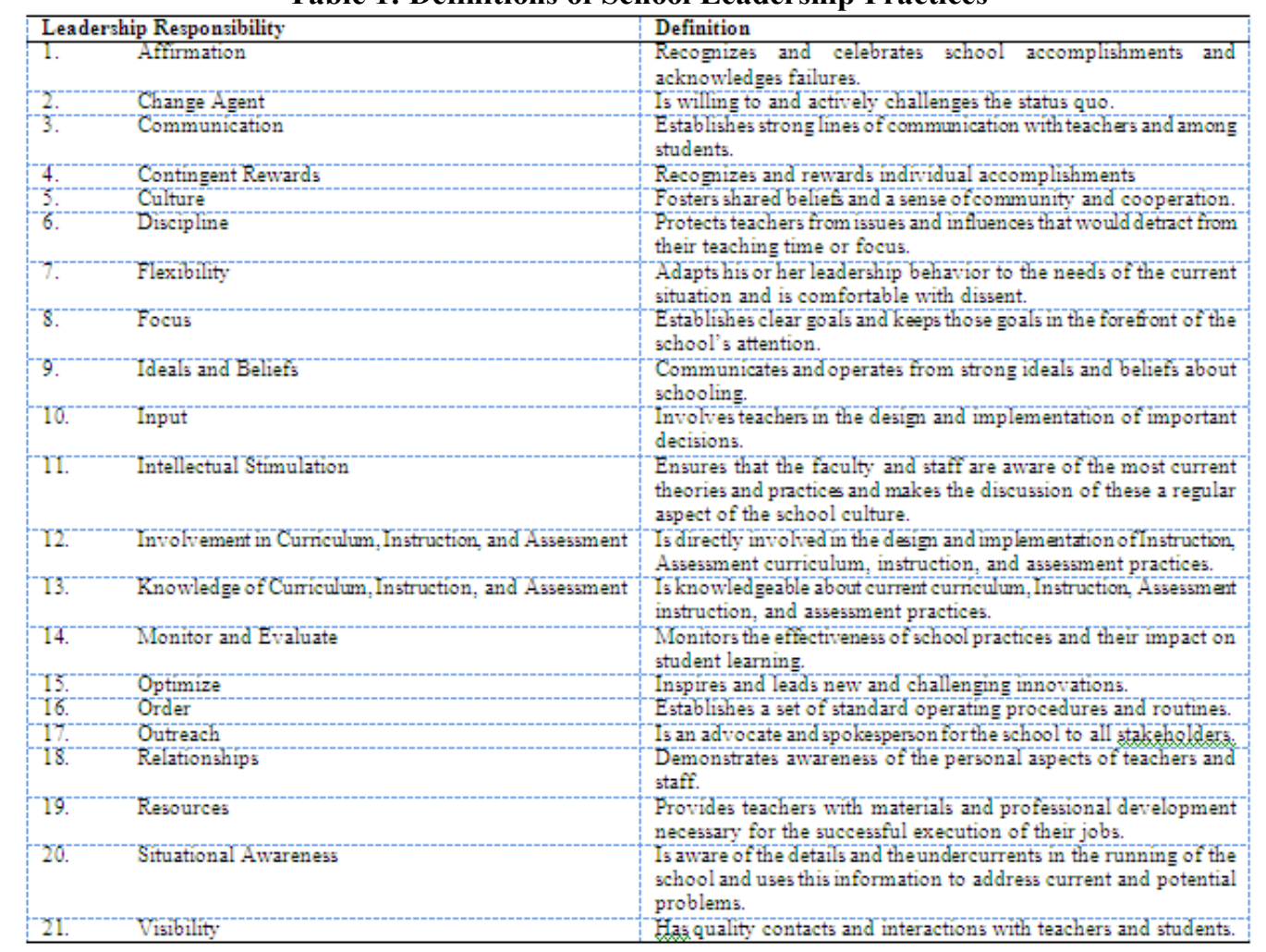

Source: Marzano, Waters, \& McNulty (2005), pp. 42-43.

Ukeje \& Okorie (1990) hold that analysis of the Path-Goal Contingency Theory leads to the identification of three effectiveness indicators. These are perception of the leaders' reputation; feelings of levels of satisfaction of the members; and organizational goal achievement. Oduwaiye (2006) takes a cue from Ukeje \& Okorie (1990) by using morale; faculty performance and their satisfaction to measure administrative effectiveness. This study uses leadership responsibility as enunciated by Marzano, Waters, \& McNulty (2005) as the theoretical framework defining administrative effectiveness for Provosts surveyed.

\section{The Domains Of Emotional Intelligence}

Lash (2009) defines emotional intelligence as the capacity for recognizing our own feelings and those of others, for motivating ourselves, for managing emotions well in us and in our relationships. Emotional Intelligence (EI) was first introduced into intellectual discourse by Mayer and Salovey (cited in Aremu \& Tejumola, 2008) when they defined emotional intelligence as a type of social intelligence that involves the ability to monitor one's own and other's emotions, to discriminate among them, and to use the information to guide one's thinking and actions. According to Aremu \& Tejumola (2008), the definition offered by Mayer and Salovey revealed the origin of emotional intelligence from the concept of social intelligence which was propounded by Thorndike in 1920. Social intelligence could be described as the ability to understand and 
manage men and women, boys and girls to act wisely in human relations. Goleman (2006) offered a definition of emotional intelligence as the capacity for recognizing our own feelings and those of others, for motivating ourselves, and for managing emotions well in ourselves and in our relationships.

Goleman (2001) conceptualized emotional intelligence theory in terms of emotional competencies. These competencies could be described as learned capability based on emotional intelligence that results in outstanding performance at work. In other words, an emotional intelligence competency is an ability to recognize, understand, and use emotional information about oneself or others that leads to or causes effective or superior performance. Goleman (2001) identifies five domains of emotional intelligence which encompass 25 competencies. These competencies involving self awareness, self regulation, motivation, empathy and social skills were later collapsed into 20 and the five domains into the now popular four: self awareness, self management, social awareness, and relationship management (Boyatzis, Goleman, \&Rhee 2000). These are analyzed below:

\subsection{Self-Awareness}

Self-awareness is the ability to honestly reflect on and understand one's emotions, strengths, challenges, motives, values, goals, and dreams. Self-awareness provides the foundation on which the other three domains (self-management, social awareness, and relationship management) build. Without first adequately knowing and understanding self, it is difficult to manage one's emotions, accurately assess emotions in others, or to use that information to manage one's relationships with others. These competencies enable a leader to be conscious of personal limitations and use personal strengths to further the work of achieving organizational goals. In the model of emotional intelligence proposed by Goleman, Boyatzis, \& McKee (2002), self-awareness includes three personal competencies:

1.1.1 Emotional Self-Awareness: This means knowing what one feels and why. It is the ability to effectively read how one reacts to cues in the environment and be aware of how one's emotions affect performance.

1.1.2 Accurate Self-Assessment: This means knowing one's abilities and limitations, seek out feedback and learn from their mistakes, and know where they need to improve and when to work with others who have complementary strengths.

1.1.3 Self Confidence: Self-Confidence is a belief in one's own capability to accomplish a task and select an effective approach to a task or problem.

\subsection{Self Management}

According to Goleman, Boyatzis, \& McKee (2002), self-management is equated to an ongoing inner conversation and is the component of emotional intelligence that frees us from being a prisoner of our feelings. It is what allows the mental clarity and concentrated energy that leadership demands, and what keeps disruptive emotions from throwing us off track. Without effective self-management, it is difficult to reach one's personal goals and dreams let alone to lead an organization to realizing its goals and dreams. Managing one's emotions and being open to others about one's feelings, beliefs, and actions helps to establish trust, integrity, and personal capital. These are key ingredients in developing healthy working relationships and a culture and climate that is conducive to furthering the work of organizational leadership. Self Management encompasses six personal competencies:

3.2.1 Emotional Self-Control: This could be described as the ability to keep one's impulsive feelings and emotions under control and restrain negative actions when provoked, when faced with opposition or hostility from others, or when working under pressure.

3.2.2 Transparency: This is having one's actions consistent with what one says. It includes communicating intentions, ideas, and feelings openly and directly, and welcoming openness and honesty, even in difficult situations with multiple parties involved.

3.2.3 Adaptability: Adaptability is the ability to be flexible and work effectively within a variety of changing situations, and with various individuals or groups.

3.2.4 Achievement Orientation: This competence refers to a striving to continually improve performance. Achievement is not just accomplishing things. Rather, it is accomplishing things through one's own efforts, against a clear, challenging standard of excellence.

3.2.5 Initiative: Initiative is the ability to identify a problem, obstacle, or opportunity and take action in light of that to address current or future problems or opportunities. Initiative should be seen in the context of proactively doing things. Those with the initiative competence act before being forced to do so by external events.

3.2.6 Optimism: This is defined as the persistence to pursue goals despite obstacles and setbacks. 


\subsection{Social Awareness}

Social awareness allows a leader to monitor and adjust strategy, direction, and work toward accomplishing a shared vision. It helps a leader know when to push and capitalize on the momentum of the group and when to pull back and encourage reflection and collective re-examination of purpose and priorities. Social awareness is comprised of three social competencies:

3.3.1 Empathy: This gives people an astute awareness of others' emotions, concerns, and needs. The empathic individual can read emotional currents, picking up on nonverbal cues such as tone of voice or facial expression (Goleman, 2005).

3.3.2 Organizational Awareness: Refers to one's ability to understand and learn the internal and external power relationships in an organization. Sometimes called political savvy, the organizational awareness competency includes one's ability to identify real decision-makers and individuals with influence (Goleman, 2005). Ability to read situations objectively, without the distorting lens of their own biases and assumptions, allows individuals to respond effectively.

3.3.3 Service Orientation: This is a desire to help or serve others, in order to meet their needs.

\subsection{Relationship Management}

In the leadership setting, relationship management is building rapport and nurturing the capacity in others to share leadership. Relationship management is cultivating webs of relationships, finding common ground, and using shared vision to motivate people to move forward toward accomplishing a mission or goal. It involves seven social competencies:

3.4.1 Developing Others: Developing others involves sensing people's developmental needs and building their abilities.

3.4.2 Inspirational Leadership: This implies a desire to lead others. Inspirational leaders are able to articulate and arouse enthusiasm for a shared vision and mission, to step forward as needed, to guide the performance of others while holding them accountable, and to lead by example. Leadership studies have shown the more positive the style of a leader, the more positive, helpful, and cooperative are those in the group (Okorie, 2002).

3.4.3 Influence: Is the ability to persuade, convince, or impact others in order to get them to support a specific agenda or course of action.

3.4.4 Conflict Management: Conflict Management is the ability to handle difficult individuals, groups of people, or tense situations with diplomacy and tact. This competency entails finding the best solution to a given problem or disagreement. A talent of those skilled in the conflict management competence is spotting trouble as it is brewing and taking steps to calm those involved.

3.4.5 Teamwork and Collaboration: Represents the ability to work cooperatively with others, to be part of a team, to work together as opposed to working separately or competitively. It means working with others toward shared goals, and creating group synergy in pursuing collective goals.

3.4.6 Change Catalyst: This skill has to do with the effectiveness of the strategies used to facilitate change initiatives. The ability to be a cooperative member of one's social group is associated with perceptions of effectiveness in introducing change.

3.4.7 Building bonds: This is the ability to develop and maintain working relationships with various internal and external parties.

\section{Statement Of The Problem}

Schools need administrators who can manage the daily stressors of the job and who are able to lead teachers through the current school change and reform efforts. In such a complex and changing environment, a school administrator must be able to articulate a vision for success, inspire others to embrace the vision, and have the ability to make the necessary changes happen. The problem to be investigated in this study concerns the relationship between provost's emotional intelligence and administrative effectiveness in Federal Training Centres in Nigeria. Also, the study investigates into the correlations between specific domains of emotional intelligence (self-awareness, self-management, social awareness, and relationship management) and administrative effectiveness of a school leader. And lastly, the study juxtaposes the self-rating report of the Provosts on emotional intelligence with their teachers' perception for empirical classification.

\section{Purpose Of The Study}

The purpose of this study was to determine if a relationship exists between Provost's Emotional Intelligence and administrative effectiveness. Goleman (2005) argues that what leaders must be responsive to demands that they be emotionally intelligent, as well as intellectually competent. Heart and head leadership is more effective than either one alone. The study has as its specific objectives the following: 
i. To determine if a relationship exists between emotional intelligence and administrative effectiveness of school leader.

ii. To seek to identify the level of correlation of the four domains of emotional intelligence with the administrative effectiveness competencies of school leader.

iii. To ascertain the reliability of school leader's self rating methods of emotional intelligence.

\section{Research Questions}

The following research questions were raised to guide the study:

i. Do principals employ emotional intelligence competencies in their administrative practices?

ii. What specific Administrative Effectiveness competencies are used by the principals?

\section{Research Hypotheses}

Ho: There is no significant relationship between the emotional intelligence and administrative effectiveness of a provost.

Ho1: There is no significant relationship between self-awareness competence and Provost's administrative effectiveness competencies.

Ho2: There is no significant relationship between self-management competence and Provost's administrative effectiveness competencies.

Ho3: There is no significant relationship between social-awareness competence and Provost's administrative effectiveness competencies.

Ho4: There is no significant relationship between relationship management competence and Provost's administrative effectiveness competencies.

Ho5: There is no significant difference between the Provost's Self-Rating Report on Emotional Intelligence and administrative effectiveness and Teachers' perception of his or her Emotional Intelligence and administrative effectiveness.

VIII. Sample And Sampling Technique

The population of the study consisted of 6 Provosts, 6 Deputy Provosts, and 149 teachers of the Federal Training Centres in Calabar, Enugu Ilorin, Kaduna, Lagos, and Maiduguri.

\section{Research Instrument}

Data for this research work were collected through the use of questionnaire titled "Administrative Effectiveness and Emotional Intelligence Questionnaire (AEEIQ)". 3-point Likert rating scale (from "Always" to "Never") was used to obtain interval data related to the frequency that each participant engaged in the behaviors described on the survey.

\section{Validity And Reliability Of The Instrument}

To ensure the reliability and validity of the study, the instrument was adapted from empirical studies by Marzano, Waters, \& McNulty (2005) to design survey on administrative effectiveness competencies. Emotional Intelligence was measured using a valid and reliable instrument (Emotional Competencies Profiler) (Wolmarans $\&$ Martins, 2001). The reliability of this instrument has been found to be 0.981 with acceptable content validity (Coetzee, Martins, Basson, \& Muller, 2006). The items were as well given to experts in educational management and managerial psychology for vetting.

\section{Procedure For Data Collection}

The research instrument was administered by the researcher to collect information from Provosts, Deputy Provosts and the academic staff of the 6 Federal Training Centres situated in the six geo-political zone of Nigeria. Letters were written to the participants explaining to them the purpose of the study and sought their cooperation. The participants were provided with an explanation on the questions they may not understand.

\section{Data Analysis}

Mean and standard deviation were calculated for each question on the survey. Pearson product-moment correlation coefficient and t-test statistical analyses were conducted to determine the level of correlation between Emotional Intelligence and Administrative effectiveness. Pearson product-moment was used to test hypotheses $\mathrm{H} 01$ through $\mathrm{H} 04$ while t-test statistical analysis was used to test H05 to ascertain the degree of difference. All hypotheses were tested at .05 significance level. 


\section{Findings Related To Research Questions}

13.1 Research Question No 1: Do provosts employ emotional intelligence competencies in their administrative practices?

Table 2: Provost's Emotional Intelligence

\begin{tabular}{llccc}
\hline S/NO & ITEM & FREQUENCY & TOTAL RESPONSES & MEAN \\
\hline 1 & Self Awareness & 60 & 180 & 3 \\
2 & Self Management & 96 & 288 & 3 \\
3 & Social Awareness & 48 & 144 & 3 \\
4 & Relationship Management & 96 & 288 & 3 \\
\hline TOTAL & & & & $\mathbf{1 2}$ \\
AVERAGE & & & $\mathbf{3}$ \\
\hline
\end{tabular}

Table 2 shows provost's emotional intelligence. The average emotional intelligence is 3 . The answer to the first research question is yes; indicating that all the principals used self awareness, self management, social awareness, and relationship management in planning and administration of the school system.

13.2 Research Question No 2: What specific Administrative Effectiveness competencies are used by the principals?

\begin{tabular}{|c|c|c|c|c|}
\hline S/NO & ITEM & FREQUENCY & TOTAL RESPONSES & MEAN \\
\hline 1 & Affirmation & 24 & 63 & 2.6 \\
\hline 2 & Change Agent & 24 & 69 & 2.9 \\
\hline 3 & Contingent Rewards & 12 & 36 & 3 \\
\hline 4 & Communication & 24 & 72 & 3 \\
\hline 5 & Culture & 24 & 66 & 2.8 \\
\hline 6 & Discipline & 12 & 30 & 2.5 \\
\hline 7 & Flexibility & 24 & 72 & 3 \\
\hline 8 & Focus & 36 & 102 & 2.8 \\
\hline 9 & Ideals and Beliefs & 24 & 72 & 3 \\
\hline 10 & Input & 12 & 36 & 3 \\
\hline 11 & Intellectual Simulation & 24 & 66 & 2.8 \\
\hline 12 & $\begin{array}{l}\text { Involvement in Curriculum, Instruction and } \\
\text { Assessment }\end{array}$ & 12 & 30 & 2.5 \\
\hline 13 & $\begin{array}{l}\text { Knowledge of Curriculum, Instruction and } \\
\text { Assessment }\end{array}$ & 12 & 33 & 2.8 \\
\hline 14 & Monitoring and Evaluation & 12 & 30 & 2.5 \\
\hline 15 & Optimizer & 12 & 36 & 3 \\
\hline 16 & Order & 12 & 36 & 3 \\
\hline 17 & Outreach & 12 & 33 & 2.8 \\
\hline 18 & Relationships & 12 & 36 & 3 \\
\hline 19 & Resources & 24 & 63 & 2.6 \\
\hline 20 & Situational Awareness & 12 & 36 & 3 \\
\hline 21 & Visibility & 36 & 105 & 2.9 \\
\hline Total & & & & 59.5 \\
\hline Average & & & & 2.8 \\
\hline
\end{tabular}

Table 3 shows provost's administrative effectiveness competencies. The average mean is 2.8 . Five (23.9\%) had less than average mean of 2.8, while 11 (52.4) had above average mean of 2.8. this implies that majority of administrative competencies are exhibited by the Provosts in the survey. The administrative effectiveness competencies with the highest mean (3) were Contingent Reward, Communication, Flexibility, Ideals and Beliefs, Inputs, Optimizer, Order, Relationships, and Situational Awareness. This implies that the principals recognize and celebrate accomplishments, establish strong lines of communication with teachers and students, adapts his/her behavior to specific situations, communicates and operates from strong ideals and beliefs about schooling, inspires and leads new and challenging innovations, establish a set of standard operating procedures and routines, demonstrate awareness of the personal aspects of teachers and staff, and is aware of what goes on within the school and uses that awareness to further educational mission and objectives.

XIV. Hypotheses Testing

14.1 Ho: There is no significant relationship between the emotional intelligence and administrative effectiveness of a provost.

Table 4: Emotional Intelligence and Administrative Effectiveness of a Provost

\begin{tabular}{cccccccr}
\hline Variable & $\mathrm{N}$ & $\mathrm{X}$ & $\mathrm{SD}$ & $\mathrm{df}$ & $\begin{array}{c}\text { Calculated } \\
\text { r-value }\end{array}$ & $\begin{array}{c}\text { Critical } \\
\text { r-value }\end{array}$ & Decision \\
\hline Emotional Intelligence & 12 & 4.43 & 3.65 & 11 & .785 & .532 & Ho Rejected \\
$\begin{array}{c}\text { Administrative } \\
\text { Effectiveness }\end{array}$ & 12 & 5.92 & 3.96 & & & & \\
\hline
\end{tabular}


Table 4 indicates that the calculated r-value (.785) is greater that critical r-value $(.532)$ at .05 for 11 degrees of freedom. Hence, the null hypothesis which states that there is no significant relationship between the emotional intelligence and administrative effectiveness of the provost is rejected.

14.2 Ho1: There is no significant relationship between self-awareness competence and Provost's administrative effectiveness competencies

Table 5: Self-awareness competence and Provost's administrative effectiveness competencies

\begin{tabular}{|c|c|c|c|c|c|c|c|}
\hline Variable & $\mathrm{N}$ & $\mathrm{X}$ & SD & df & $\begin{array}{c}\text { Calculated } \\
\text { r-value }\end{array}$ & $\begin{array}{l}\text { Critical } \\
\text { r-value }\end{array}$ & Decision \\
\hline \multirow[t]{2}{*}{ Self-Awareness Competence } & 12 & 4.83 & 2.69 & & & & \\
\hline & & & & 11 & .727 & .532 & Ho1 Rejected \\
\hline $\begin{array}{l}\text { Administrative } \\
\text { Effectiveness }\end{array}$ & 12 & 5.92 & 3.96 & & & & \\
\hline
\end{tabular}

Table 5 indicates that the calculated r-value (.727) is greater than the critical r-value (.532) at .05 level of significance for 11 degrees of freedom. Thus, the null hypothesis is rejected.

14.3 Ho2: There is no significant relationship between self-management and Provost's administrative effectiveness competencies.

Table 6: Self-management competence and Provost's administrative effectiveness competencies.

\begin{tabular}{cccccccr}
\hline Variable & $\mathrm{N}$ & $\mathrm{X}$ & $\mathrm{SD}$ & $\mathrm{df}$ & $\begin{array}{c}\text { Calculated } \\
\text { r-value }\end{array}$ & $\begin{array}{c}\text { Critical } \\
\text { r-value }\end{array}$ & Decision \\
\hline $\begin{array}{c}\text { Self Management } \\
\text { Competence }\end{array}$ & 12 & 3.11 & 2.99 & & & .535 & Ho2 Rejected \\
$\begin{array}{c}\text { Administrative } \\
\text { Effectiveness }\end{array}$ & 12 & 5.92 & 3.96 & 11 & .935 & \\
\hline
\end{tabular}

From Table 6, the calculated r-value (.935) is greater than the critical r-value (.532) at .05 level of significance for 11 degrees of freedom. The null hypothesis that there is no significant relationship between selfmanagement competence and provost's administrative effectiveness is rejected.

14.4 Ho3: There is no significant relationship between social-awareness competence and provost's administrative effectiveness competencies.

Table 7: Social awareness competence and provost's administrative effectiveness competencies.

\begin{tabular}{lccccccr}
\hline Variable & $\mathrm{N}$ & $\mathrm{X}$ & $\mathrm{SD}$ & $\mathrm{df}$ & $\begin{array}{c}\text { Calculated } \\
\text { r-value }\end{array}$ & $\begin{array}{c}\text { Critical r- } \\
\text { value }\end{array}$ & Decision \\
\hline $\begin{array}{l}\text { Social Awareness } \\
\text { Competence }\end{array}$ & 12 & 3.86 & 2.95 & & & .812 & .532 \\
$\begin{array}{l}\text { Administrative } \\
\text { Effectiveness }\end{array}$ & 12 & 5.92 & 3.96 & & & Ho3 Rejected \\
\hline
\end{tabular}

As shown in Table 7, the calculated r-value (.812) is greater than the critical r-value (.532) at .05 level of significance for 11 degrees of freedom. Hence, the null hypothesis is rejected.

14.5 Ho4: There is no significant relationship between relationship management competence and provost's administrative effectiveness competencies.

Table 8: Relationship management and provost's administrative effectiveness competencies.

\begin{tabular}{cccccccc}
\hline Variable & $\mathrm{N}$ & $\mathrm{X}$ & $\mathrm{SD}$ & $\mathrm{df}$ & $\begin{array}{c}\text { Calculated } \\
\text { r-value }\end{array}$ & $\begin{array}{c}\text { Critical } \\
\text { r-value }\end{array}$ & Decision \\
\hline $\begin{array}{c}\text { Relationship Management } \\
\text { Competence }\end{array}$ & 12 & 4.63 & 3.64 & & & .532 & Ho4 Rejected \\
$\begin{array}{c}\text { Administrative } \\
\text { Effectiveness }\end{array}$ & 12 & 5.92 & 3.96 & & & & \\
\hline
\end{tabular}

From Table 8, the calculated r-value (.593) is greater than the critical r-value (.532) at .05 level of significance for 11 degrees of freedom. Hence, the null hypothesis is rejected. 
14.6 H05: There is no significant difference between the provost's self-rating on emotional intelligence and the teachers' perception of his/her emotional intelligence.

Table 9: Provost's self-rating on emotional intelligence and the teachers' perception of his/her emotional intelligence.

\begin{tabular}{llllllll}
\hline Variable & $\mathrm{N}$ & $\mathrm{X}$ & $\mathrm{SD}$ & $\mathrm{df}$ & $\begin{array}{l}\text { Calculated } \\
\text { r-value }\end{array}$ & $\begin{array}{l}\text { Critical } \\
\text { value }\end{array}$ & $\begin{array}{c}\text { r- } \\
\text { Decision }\end{array}$ \\
\hline Self-Rating Method & 12 & 7.32 & 4.93 & \multirow{2}{*}{159} & 1.72 & 1.96 & Ho Accepted \\
Teachers' Perception & 149 & 13.89 & 8.77 & & & & \\
\hline
\end{tabular}

Table 9 shows that the calculated t-value (1.72) is less than critical t-value (1.96) at .05 level of significance for 159 degrees of freedom. Hence, the null hypothesis which states that there is no significant difference between Provost's self-rating on emotional intelligence and teachers' perception of his/her emotional intelligence is therefore, accepted.

\section{Major Findings}

The major findings from this study include:

i. There is significant relationship between Provost's emotional intelligence and the Provost's administrative effectiveness.

ii. There is significant relationship between Provost's self-awareness competencies and the Provost's administrative effectiveness.

iii. There is significant relationship between Provost's self-management competencies and the Provost's administrative effectiveness.

iv. There is significant relationship between Provost's social-awareness competencies and the Provost's administrative effectiveness.

v. There is significant relationship between Provost's relationship management competencies and the Provost's administrative effectiveness.

vi. There is no significant difference between the Provost's self-rating on emotional intelligence and the Teachers' perception of the Provost's emotional intelligence.

\section{Discussion Of Findings}

\subsection{Provost's Emotional Intelligence and Administrative Effectiveness}

The result of main hypothesis Ho indicates that emotional intelligence of the provost has a great influence on his/her administrative effectiveness. Emotional intelligence in the leader makes a difference in how effectively that leader leads as evidenced by what the leader is able to accomplish. Emotional intelligence may assist principals as they strive to meet student needs. The finding confirms Beavers (2005) and Mayer, Salovey, and Caruso (2004) that the emotional intelligence of the school head would in no small measure enhance his/her administrative effectiveness, thereby achieving the stated school goals and objectives.

\subsection{Self Awareness Competence and Administrative Effectiveness}

This study discovered that there is a significant relationship between provost's self awareness competence and his/her administrative effectiveness. Self awareness is the ability to honestly reflect on and understand one's emotion, strength, challenges, motives, values, goals, and dreams. Salami (2007) and Goleman (2005) affirmed that Provost who is conscious of himself would be more committed to his/her career and organization.

\subsection{Self Management Competence and Administrative Effectiveness}

The result of hypothesis Ho2 showed that self management and administrative effectiveness of the provost are significantly related. This is in line with position of Goleman, Boyatzis, and Mckee (2002) that provost's ability to manage his own emotions and being open to others about one's feelings, beliefs, and actions helps to establish trust, and integrity. These are key ingredients in developing and maintaining a healthy working relationship, and a culture and climate conducive to furthering the work of organizational leadership.

\subsection{Social Awareness Competence and Administrative Effectiveness}

This study revealed that there is a significant relationship between social awareness and administrative effectiveness competencies. Social awareness allows a provost to monitor and adjust strategy, direction, and work towards goals accomplishment. Spencer and Spencer (1993), in their studies, submitted that the ability to read other's needs well comes naturally to the best principals of product development teams (cited in Fall (2004). Attuned to how others feel in the moment, a principal can say and do what's appropriate, whether it be 
to calm fears, assuage anger, or join in good spirits. This would enable the principal to relate effectively with both staff and students so as to achieve the school goals and objectives.

\subsection{Relationship Management Competence and Administrative Effectiveness}

The result of hypothesis Ho4 revealed that provost's relationship management cannot be isolated from his/her administrative effectiveness competencies. This study agreed with studies by Farinmade (2010) and Goleman, Boyatzis, Mckee (2002) that a principal who creates a cordial working atmosphere in the school system and carry his/her staff along towards the direction of goals achievement, would receive genuine cooperation from his/her staff. Relationship management is building rapport and nurturing the capacity in order to share leadership.

\subsection{Provost Self Rating and the Teachers' Perception of His/her Emotional Intelligence}

The result of the hypothesis Ho5 revealed that the perception of the provost's own emotional intelligence is not different from teachers' perception. Fall (2004) in a study involving 31 principals (and 299 teachers) also showed that principals who are emotionally self aware were more likely to rate themselves similar to how teachers perceive them. This establishes the fact that self assessment could be relied on in making a decision about an issue.

\section{Conclusion}

Data from this study indicate there is a strong correlation between emotional intelligence and administrative effectiveness of the Provosts of Federal Training Centres. The study showed strong correlations between the four domains and 25 competencies of emotional intelligence. The strongest correlations are found within the domain of self-management competence (.935). This study revealed that provosts who are, or who learn to be, more emotionally intelligent may be more likely to be effective in school administration. As the level of emotional intelligence increases, the administrative effectiveness may also increase. Provosts who develop and practice the competencies of emotional intelligence may be better positioned to deal with the demands and complexities of school leadership in the twenty-first century.

With the education sector in Nigeria operating in a complex and challenging environment characterized with frequent policy changes, and with the stress inherent in leadership, leaders are constantly feeling threatened in one way or another. This makes emotional intelligence more relevant now. Understanding others enables us to more effectively motivate individuals and guide groups, teams, and organizational cultures. Clearly, the demands placed upon school leaders in the twenty-first century call for leadership that is strong both intellectually and emotionally. Emotionally intelligent leadership matters to those seeking to be effective school leaders.

\section{Implications For Theory And Practice}

The study was concerned with emotional intelligence and administrative effectiveness of provosts of Federal Training Centres in Nigeria. Federal Training Centres situated in the six geo-political zones of Nigeria (Calabar, Enugu, Ilorin, Kaduna, Lagos, and Maiduguri) were set up to train and develop both low and middle manpower in the Federal and State Civil Service. Determining a relationship between emotional intelligence and administrative effectiveness could provide a compelling case for recruitment of provosts with emotional intelligence and developing emotional intelligence in them. Measures of emotional intelligence and administrative effectiveness of school heads could be used in the professional development and evaluation of school leaders. When a school head is aware of his strengths and deficits in emotional intelligence and leadership responsibilities that could enhance student achievement, such a school leader would be able to leverage those strengths and mitigate weaknesses to increase his effectiveness as school leader. This will consequently, impact positively on the academic achievement of the students which constitute the ultimate goal of the school.

\section{Recommendations}

Given the findings and conclusions from this study, the following recommendations are proposed:

i. Provosts should develop and regularly update themselves on the four domains of emotional intelligence through book studies, workshops, seminars, conferences, conversations between those who know about emotional intelligence, etc. ;

ii. Attention should be paid to emotional intelligence in the appointment of school principal. This is likely to enhance appointment of school leaders who will engage in effective school leadership practices shown to ensure school effectiveness.

iii. School principals should acquaint themselves with school leadership practices that are said empirically to ensure improved student performance. 
iv. Teaching Service Commission should provide in-service professional development for practicing school leaders on how to use emotional intelligence to effectively lead collaborative efforts in schools.

\section{References}

[1] Oduwaiye, R. O. (2006). Role conflict and administrative effectiveness of vice-principals of public secondary schools in Kwara State, Nigeria: implications for their morale. Journal of Education Studies, 4(2), 94-105.

[2] Nwagu, C.C. (1999). Issues and strategies in the evaluation of administrative performance of heads of educational institutions. In Studies in Educational Planning and Administration (SEPA). A journal of the National Institute for Educational Planning and Administration (NIEPA), Nigeria, 2(1), 32-38

[3] Lash, R. (2009). Emotional intelligence and leadership. The $21^{\text {st }}$ Century Effective Manager, 1, 11-13

[4] Aremu, A.O. \& Tejumola, T.O. (2008). Assessment of emotional intelligence among Nigerian Police. Journal of Social Sciences, $16(3), 221-226$

[5] Goleman, D. (2006). The socially intelligent leader. Educational Leadership, 64(1), 76-81

[6] Coetzee, M., Martins, N., Basson, J.S. \& Muller, H. (2006). The relationship between personality preferences, self-esteem and emotional competence. SA Journal of Industrial Psychology, 32 (2), 64-73

[7] Beavers, M. M. (2005). Emotional intelligence, school leaders and high-performing high- poverty middle schools in the state of Virginia. Dissertation Abstracts International, 66 (2446), 07A. (UMI No. AAI13182193).

[8] Mayer, J., Salovey, P., \& Caruso, D. (2004). Emotional intelligence: Theory, findings, and implications. Psychological Inquiry, $15(3), 197-215$.

[9] Salami, S.O. (2007). Relationships of emotional intelligence and self-efficacy to work attitudes among secondary schools teachers in southwestern Nigeria. Essays in Education, 20, 43-56.

[10] Fall, M. J. (2004). Emotional competencies as a factor in the leadership of elementary school principals. Dissertation Abstracts International, 65(3699), 10A. (UMI No. sAAT3150970)

[11] Marzano, R. J., Waters, T., \& McNulty, B. A. (2005). School leadership that works: From research to results. Alexandria, VA: Association for Supervision and Curriculum Development.

[12] Goleman, D., Boyatzis, R., \& McKee, A. (2002). Primal leadership: Realizing the power of emotional intelligence. Boston, MA: Harvard Business School Press.

[13] Ukeje, B.O., \& Okorie, N. (1990). Leadership in educational organization. Port Harcourt: Pam Unique Publishing Co.

[14] Goleman, D. (2001). An ei-based theory of performance. In C. Cherniss and D. Goleman (Eds.), The emotionally intelligent workplace. San Francisco: Jossey-Bass.

[15] Boyatzis, R., Goleman, D., \& Rhee, K. (2000). Clustering competence in emotional intelligence: Insights from the emotional competence inventory. In R. Bar-On \& J. Parker (Ed.), The Handbook of Emotional Intelligence: Theory, Development, Assessment, and Application at Home, School, and in the Workplace (pp. 343-362). San Francisco: Jossey-Bass.

[16] Okorie, A.N. (2002). Leadership in schools. In F. Durosaro \& S. Ogunsaju. The craft of educational management (eds). Ilorin: Indemac Print Media.

[17] Wolmarans, I.S. \& Martins, N. (2001). The $360^{\circ}$ Emotional Competency Profiler. Unpublished manual. Johannesburg: Organisational Diagnostics and Learning Link International.

[18] Farinmade, F.K. (2010). Principal's human relations strategies and students academic performance in Ikenne Local Government, Ogun State. Unpublished dissertation, Department of Educational Management, University of Ilorin, Nigeria.

[19] Rob, J. (2010). The four quadrants of administrative effectiveness. Retrieved from http://chronicle.com/article/The-Four-Quadrantsof-Administrative Effectiveness/123642 